\title{
Distributional Patterns of Alien Plants in China: The Relative Importance of Phylogenetic History and Functional Attributes
}

\author{
Youhua Chen \\ Department of Zoology, University of British Columbia, Vancouver, BC, Canada V6T $1 Z 4$ \\ Correspondence should be addressed to Youhua Chen; haydi@126.com
}

Received 27 May 2013; Accepted 15 July 2013

Academic Editors: A. Chappelka and P. Rey

Copyright ( 2013 Youhua Chen. This is an open access article distributed under the Creative Commons Attribution License, which permits unrestricted use, distribution, and reproduction in any medium, provided the original work is properly cited.

\begin{abstract}
Distribution patterns of alien species in nonnative ranges might be driven by a combination of various mechanisms, including phylogenetic history, competition for resource, environmental filtering, and so on. Both phylogenetic and functional limitations might work synergistically to determine the distribution of alien species. In this report, by utilizing the information of provincial distribution, functional attributes, and phylogeny for 95 alien species of China, the corresponding phylogenetic and functional community structures are evaluated. The results show that introduction pathway, life form, and flowering time of alien plants of China processed significant phylogenetic clustering patterns, while both the origin of distribution and reproduction mode of alien species showed phylogenetic overdispersion patterns, as revealed by NRI/NTI indices. The phylogenetic signal tests using Pagel's $\lambda$ statistic and Blomberg et al.s $K$ statistic further verified the previous patterns, even though there are some inconsistencies. Through partial Mantel test, it is found that compositional patterns of alien plant community were mainly affected by phylogenetic limitation but not functional limitation. Conclusively, phylogeny plays a more important role in structuring provincial distribution of alien plants in China.
\end{abstract}

\section{Introduction}

Alien species may possess novel functional traits for successful colonization of new habitats, in addition to random events or similar traits to native species [1-3]. However, some recent studies have pointed out that phylogeny is also playing some role on influencing alien diversity and distribution patterns [4-7]. Functional attributes and phylogenetic history reflected different facets of biological diversity, and the growing trend in ecological studies nowadays is to combine both to address the questions related to the diversity [8-10], distribution [11], and ecosystem functioning [12,13].

The application of combining both functional and phylogenetic filtering simultaneously to understand the distributional pattern of alien species in nonnative ranges has been concerned in recent studies [14]. It would be of great value to explore their interplay using alien species as the studied model. Alien species have expanded their distributional ranges in recent decades due to globalization and modernization [15], the processes of which required the rapid ecological adaptation $[16,17]$. The rapid range expansion indicated the functional uniqueness or commonness of traits when compared alien and native plants $[1,3]$.

At another perspective, in addition to novel functional traits, species' evolutionary history might be critical to promote the invasiveness, as evidenced by some previous studies $[7,17-19]$. Phylogenetic signals have been widely found in the interaction between native and alien species [20,21]. Phylogenetical similarity for alien species with respect to native species were predicted to be more successful to invade novel areas $[4,7]$. However, there are still some controversial debates on this issue, based on the predictions of Darwin's naturalization and enemy release hypotheses [22, 23].

The success of invasiveness of species in non-native areas might be due to a combination of various physiological (e.g., life form, flowering time, and reproduction mode), morphological (invasive mode), and physical (origin of distribution and colonizing habitats) factors, which could shape the distributional patterns and phylogenetic community structure of species [7]. Of course, these factors could also constitute the functional diversity patterns of species [24]. At the meantime, the taxonomic classification and trait information of alien 
plants in China have been well documented [15, 25-27]. Environmental correlates of alien plant at provincial levels of China have been revealed too [28]. However, up to now, there are no comparative studies working on the phylogenetic community structure analysis of alien plants of China as far as I know. In light with the previous information and to fill the just-mentioned knowledge gap, the central objective of the present study is to explore functional and phylogenetic community structures of the provincial distributions of alien plants in China.

The following principal hypotheses would be tested accordingly. First, alien species' provincial distribution in China was predicted to have similar phylogenetic and functional clustering (or overdispersion) patterns because the convergence of functional traits might be related to adaptive evolution and phylogenetic conservatism [12, 29]. Further, I predicted that the imprint of phylogenetic history is more important (i.e., clustering patterns should be more remarkable in phylogenetic structure of species in comparison to functional structure). The assumption underpinning this prediction is that alien species' traits and distribution were synergistically determined by the interaction of evolutionary history, environmental filtering, and ecological adaptation because of rapid range expansion $[5,7]$.

Second, I predicted that alien plants showed phylogenetic clustering patterns within each of the functional groups for a given trait, because closely related species in their traits was expected to be closely related in their phylogenetic history $[7,18]$ for facilitating invasive success $[7,30]$. I considered five functional attributes for testing the existence of phylogenetic structure: origin of distribution, introduction pathway, flowering time, reproduction mode, and life form. I utilized and compared a suite of statistical methods for this test, including NRI/NTI indices [31], Pagel's $\lambda$ statilstic [32], and Blomberg et al.s $K$ statistic [33].

\section{Materials and Methods}

2.1. Dataset. A dataset, including both the trait information and distribution records at 28 provinces, is collected for 95 alien plant species found in China (there should be more than 100 alien plants presented in China, but only the previous 95 species have detailed information as far as I can get access) $[15,25,26,28,34]$. The following functional attributes were considered: life form, reproduction mode, flowering time, origin of distribution and introduction pathway. Rigorously speaking, origin of distribution, and introduction pathway are not functional traits, but because they are related to suitable habitat and environmental tolerance of species [35, 36], both are still treated as functional attributes (not say "traits").

When performing analyses, origin of distribution is set to have five categories: America, Europe, Asia, Africa, and Mediterranean. Flowering time is set to have five categories: spring, summer, autumn, winter, and year-around. Life form is set to have five categories: annual grass, perennial grass, liane, shrub, and arbor. Introduction pathway is set to have four categories: human, animal, human-animal, and abiotic factors. Finally, reproduction mode is set to have two categories: seed and seed-vegetative.

2.2. Construction of the Phylogenetic Tree. The phylogenetic tree for the alien species was constructed by inputting the checklist of alien plants found in China into the plant phylogeny database PHYLOMATIC [37]. The Nexus files obtained from PHYLOMATIC was imported into the community phylogenetic software PHYLOCOM (version 4.1, available at http://phylodiversity.net/phylocom/) [31]. The Angiosperm Phylogeny Group III classification [38] was taken as the background supertree $[39,40]$. Branch lengths of the resultant phylogeny was calibrated using the PHYLOCOM command "bladj" with known molecular and fossil dates of plants $[39,41,42]$. The reconstructed phylogenetic relationship for 95 alien plants was presented in Figure 1.

2.3. Construction of the Functional Dendrogram. I followed the methods introduced by previous studies $[13,24,25,43]$ to calculate the functional dendrogram using clustering analysis with alternative algorithms (including Ward, average, and complete methods). The distance matrix was constructed using the Gower distance [44]. The constructed dendrograms [44] were analyzed in subsequent analyses.

2.4. Phylogenetic and Functional Structures of Alien Plants in China. I calculated two indices, the standardized net relatedness index (NRI) and the nearest taxon index (NTI) for the distribution of 95 alien plants in China across different provinces to measure their phylogenetic and functional relatedness. These two indices $[18,31]$ were not only initially applied to phylogenetic community structure analysis but also applied to functional community analysis in my study:

$$
\begin{gathered}
\mathrm{NRI}=-\frac{\mathrm{MPD}_{\text {sample }}-\mathrm{rndMPD}_{\text {sample }}}{\mathrm{sd}\left(\mathrm{rndMPD}_{\text {sample }}\right)}, \\
\mathrm{NTI}=-\frac{\mathrm{MNTD}_{\text {sample }}-\operatorname{rndMNTD}_{\text {sample }}}{\mathrm{sd}\left(\text { rndMNTD }_{\text {sample }}\right)},
\end{gathered}
$$

where $M P D_{\text {sample }}$ represents the mean pairwise phylogenetic distance in which it finds the average distance to all other taxa in the sample for each taxon and MNTD $_{\text {sample }}$ is to calculate the nearest phylogenetic neighbor in the sample for each taxon [31]. The rndMPD sample $_{\text {and }}$ rndMNTD ${ }_{\text {sample }}$ represent the mean $M P D_{\text {sample }}$ and mean $\mathrm{MNTD}_{\text {sample }}$ from randomly generated assemblages. Negative values of both metrics indicate overdispersion, while positive values of both metrics indicate clustering [45]. These two standardized indices should follow the unit normal distribution with mean $=0$ and variance $=1$. As such, if any of the indices is larger than 1.96 (or less than -1.96), the clustering (or overdispersion) pattern identified is regarded to be statistically significant.

2.5. Phylogenetic and Functional Beta Diversity of the Distributional Patterns of Alien Plants in China. I calculated a suite of distance indices to measure phylogenetic and functional beta diversity of alien species in different provinces of China. The 


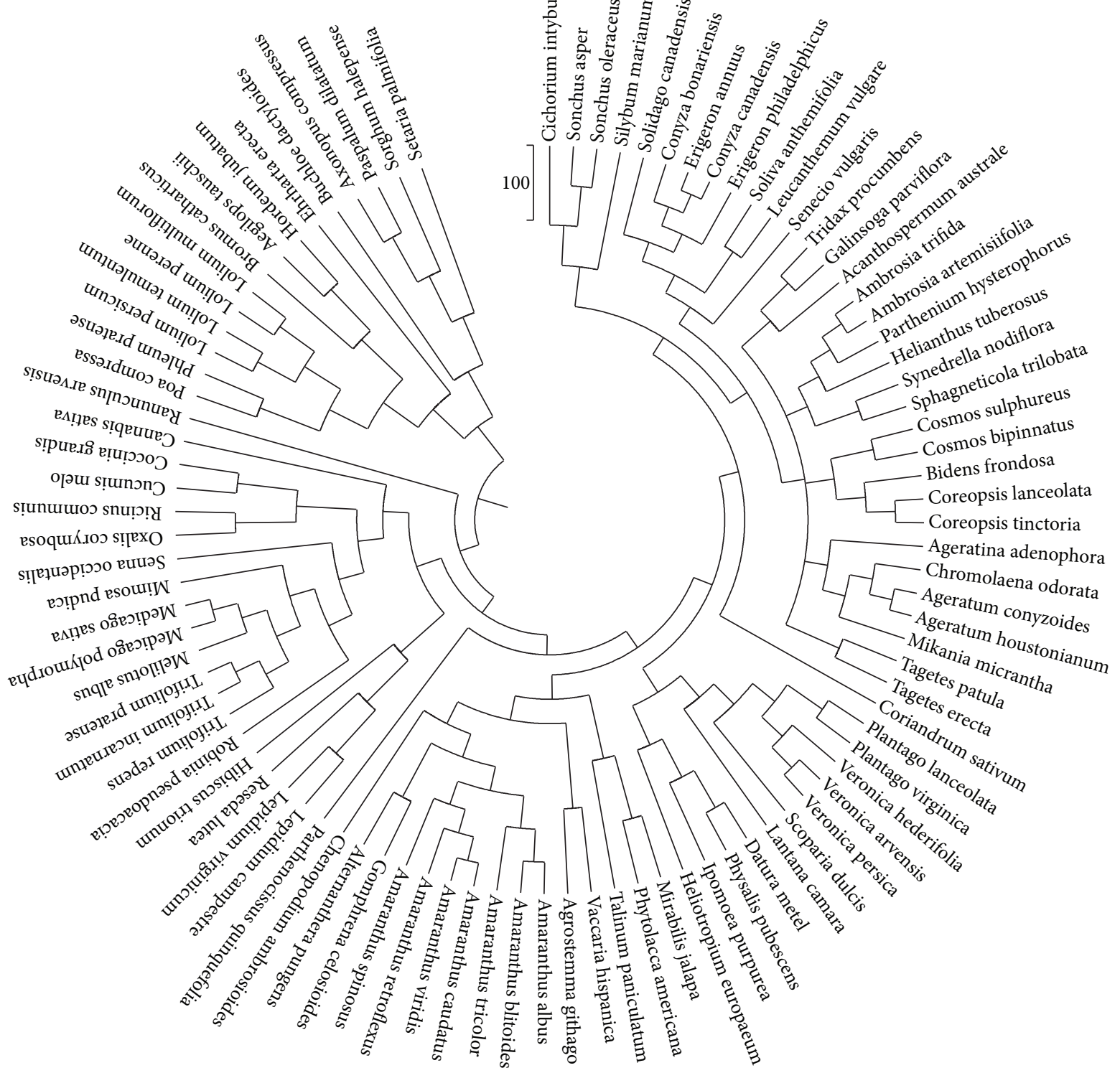

FIGURE 1: Phylogenetic relationship of 95 alien plants in China.

following presence-absence-based metrics were calculated $[10,42,46]$. Please note that all these metrics were applied to both functional dendrogram and phylogenetic cladogram comparatively.

(1) Phylogenetic Sorensen index:

$$
\text { Sorensen }=\frac{2 \mathrm{BL}_{k_{1}, k_{2}}}{\mathrm{BL}_{k_{1}}+\mathrm{BL}_{k_{2}}},
$$

where $\mathrm{BL}_{k_{1}, k_{2}}$ is the total length of the branches shared between communities $k_{1}$ and $k_{2}$, and $\mathrm{BL}_{k_{1}}$ and $\mathrm{BL}_{k_{2}}$ are the total branch lengths found in communities $k_{1}$ and $k_{2}$, respectively.

(2) UniFrac index:

$$
\text { UniFrac }=\sum_{l}^{n} \mathrm{BL}_{l}\left|\frac{k_{1 l} k_{2 l}}{k_{1 T} k_{2 T}}\right|,
$$

where $n$ is the number of branches in the phylogeny, $\mathrm{BL}_{l}$ is the length of branch $l$, and $k_{1 l}$ and $k_{2 l}$ are the numbers of species descended from branch $l$ in communities $k_{1}$ and $k_{2} \cdot k_{1 T}$ and $k_{2 T}$ are the total numbers of species in communities $k_{1}$ and $k_{2}$, respectively.

(3) $D_{\text {nn }}$ (mean nearest phylogenetic neighbor distance between two communities):

$$
D_{\mathrm{nn}}=\frac{\sum_{i=1}^{n k_{1}} \min \delta_{i k_{2}}+\sum_{j=1}^{n k_{2}} \min \delta_{j k_{1}}}{2}
$$

where $\min \delta_{i k_{2}}$ is the distance from the nearest phylogenetic neighbor in community $k_{2}$ to species $i$ in community $k_{1} . n k_{1}$ is the number of species in community $k_{1}$. The definition of $\min \delta_{j k_{1}}$ and $n k_{2}$ are analogous. 
TABLE 1: Standardized phylogenetic and functional NRI and NTI indices of alien distributional patterns across different provinces of China, both were resulted form 3000 randomization runs. " $n_{\text {taxa }}$ " indicated number of taxa included by each category of the subject.

\begin{tabular}{|c|c|c|c|c|c|}
\hline \multirow{2}{*}{ Provinces } & \multirow{2}{*}{$n_{\text {taxa }}$} & \multicolumn{2}{|c|}{ Phylogenetic structure } & \multicolumn{2}{|c|}{ Functional structure } \\
\hline & & NRI & NTI & NRI & NTI \\
\hline Anhui & 51 & 0.0672 & 1.2893 & 0.3986 & $2.2405^{*}$ \\
\hline Fujian & 40 & 0.5627 & 1.3478 & -0.769 & 0.74 \\
\hline Gansu & 23 & -0.8243 & 1.8303 & 1.1588 & 1.3872 \\
\hline Guangdong & 28 & 1.1089 & 0.2195 & -0.685 & 0.4091 \\
\hline Guangxi & 19 & 0.4537 & 1.7834 & -0.8444 & 1.3375 \\
\hline Guizhou & 24 & 0.6931 & 1.5049 & -0.0085 & 0.0406 \\
\hline Hainan & 19 & 0.3957 & $2.2743^{*}$ & -1.2845 & 0.5497 \\
\hline Hebei & 37 & 0.0808 & 1.0741 & -0.2002 & 0.1109 \\
\hline Heilongjiang & 23 & 0.4561 & 1.8209 & -0.3773 & 0.2998 \\
\hline Henan & 36 & -0.7577 & -0.1487 & 1.2417 & 1.4956 \\
\hline Hubei & 27 & 0.8247 & 1.4583 & -0.5266 & 0.8645 \\
\hline Hunan & 26 & 0.1744 & 1.2591 & 0.1695 & -0.6661 \\
\hline InnerMongolia & 18 & 0.7436 & 1.0167 & -0.56 & 1.7774 \\
\hline Jiangsu & 60 & -0.3754 & 1.1002 & 0.9637 & 1.5637 \\
\hline Jiangxi & 41 & 0.8709 & $2.1592^{*}$ & 0.1052 & 1.6498 \\
\hline Jilin & 28 & 0.7 & $3.0169^{*}$ & -0.3696 & 0.287 \\
\hline Liaoning & 43 & -0.1948 & 1.7399 & 0.7007 & 0.0467 \\
\hline Ningxia & 12 & -0.8462 & 1.4241 & 0.645 & 1.3295 \\
\hline Qinghai & 16 & -0.9771 & 1.8939 & 1.3329 & 1.9154 \\
\hline Shaanxi & 30 & 0.0528 & 1.892 & -0.4208 & -0.1863 \\
\hline Shandong & 31 & -0.9933 & 1.4148 & 1.1187 & 1.937 \\
\hline Shanxi & 22 & 0.9357 & 0.4336 & -0.6308 & -0.451 \\
\hline Sichuan & 23 & 0.3838 & -0.2776 & -0.6811 & 0.0101 \\
\hline Taiwan & 24 & 1.2828 & $2.2622^{*}$ & -0.991 & 0.7657 \\
\hline Tibet & 9 & 1.1849 & 1.532 & -0.5949 & 1.1336 \\
\hline Xinjiang & 20 & 0.0118 & $2.2115^{*}$ & 1.4543 & 1.9541 \\
\hline Yunnan & 41 & -0.279 & 0.7989 & -0.3649 & 0.9247 \\
\hline Zhejiang & 43 & 0.989 & $2.1426^{*}$ & -0.2255 & 1.449 \\
\hline
\end{tabular}

Significant values are marked by asterisks at the probability level $(P<0.05)$.

(4) $D_{\mathrm{pw}}$ (mean pairwise phylogenetic distance between two communities):

$$
D_{\mathrm{pw}}=\frac{\sum_{i=1}^{n k_{1}} \bar{\delta}_{i k_{2}}+\sum_{j=1}^{n k_{2}} \bar{\delta}_{j k_{1}}}{2}
$$

where $\bar{\delta}_{i k_{2}}$ is the mean pairwise phylogenetic distance between species $i$ in community $k_{1}$ to all the species in community $k_{2}$. The definition of $\bar{\delta}_{j k_{1}}$ is analogous.

It is worthy to mention here that the last two indices actually were very similar to $M P D_{\text {sample }}$ and $M N T D_{\text {sample }}$ indices, but being applied to pairwise communities (i.e., $D_{\mathrm{nn}}$ and $D_{\mathrm{pw}}$ indices). In contrast, $\mathrm{MPD}_{\text {sample }}$ and $\mathrm{MNTD}_{\text {sample }}$ indices are alpha indices and applied to a single community.

After generating these phylogenetic/functional distance matrices, I employed partial Mantel test $[47,48]$ to examine the independent influence of phylogenetic and functional constraints on structuring species distributional patterns of alien plants. The compositional dissimilarity (or distance) matrix constructed from species-provincial distribution matrix was used as the response matrix.

\section{Results}

3.1. Phylogenetic and Functional Structures of the Provincial Distribution of Alien Plants. As showed in Table 1, phylogenetic clustering patterns were prevailing for the distribution across different provinces (except species found in Henan Province, indicated by negative values in both metrics). In contrast, weak functional clustering patterns were observed, and two provinces showed overdispersion patterns (Shaanxi and Shanxi). Half part of other provinces has clustering patterns, while the others showed random (no clustering or overdispersion) patterns since one of the NRI/NTI indices is negative, while the other is positive. As such, the first hypothesis was supported, showing that phylogenetic history determined provincial distribution of alien plants in China but not functional attributes. 
TABLE 2: Standardized phylogenetic NRI and NTI indices of origin of distribution, flowering time, life form, reproduction mode, and introduction pathway of alien plants in China, both were resulted form 3000 randomization runs. " $n_{\text {taxa }}$ " indicated number of taxa included by each category of the subject. The columns other than the first one were the categories of each functional trait. Origin of distribution has five categories: America, Europe, Asia, Africa, and Mediterranean. Flowering time has five categories: spring, summer, autumn, winter, and year-around. Life form has five categories: annual grass, perennial grass, liane, shrub, and arbor. Introduction pathway has four categories: human, animal, human-animal, and abiotic factors. Reproduction mode has two categories: seed and seed-vegetative.

\begin{tabular}{|c|c|c|c|c|c|}
\hline Origin of distribution & America & Europe & Asia & Africa & Mediterranean \\
\hline$n_{\text {taxa }}$ & 54 & 26 & 7 & 5 & 2 \\
\hline NRI & $4.3938^{*}$ & -0.9807 & -1.1755 & -0.74 & -1.073 \\
\hline NTI & $2.2003^{*}$ & $3.2972^{*}$ & -0.1052 & -0.6513 & -1.073 \\
\hline Flowering time & Spring & Summer & Autumn & Winter & Year-around \\
\hline$\overline{n_{\text {taxa }}}$ & 11 & 73 & 3 & 2 & 6 \\
\hline NRI & 0.0641 & -1.7168 & 0.5442 & $2.4232^{*}$ & $3.6012^{*}$ \\
\hline NTI & 0.4723 & -0.9343 & 0.0473 & $2.4232^{*}$ & $2.3274^{*}$ \\
\hline Life form & Annual grass & Perennial grass & Liane & Shrub & Arbor \\
\hline$n_{\text {taxa }}$ & 38 & 48 & 2 & 5 & 2 \\
\hline NRI & $2.2197^{*}$ & -1.9583 & -0.451 & 1.2686 & 1.2801 \\
\hline NTI & 1.7923 & 0.3317 & -0.451 & 1.1359 & 1.2801 \\
\hline Introduction pathway & Human & Animal & Human-animal & Abiotic factors & \\
\hline$n_{\text {taxa }}$ & 72 & 4 & 10 & 9 & \\
\hline NRI & -3.0718 & 1.2504 & 1.3753 & $5.2115^{*}$ & \\
\hline NTI & -0.2649 & 0.811 & 1.0408 & $3.7555^{*}$ & \\
\hline Reproduction mode & Seed & Seed-vegetative & & & \\
\hline$\overline{n_{\text {taxa }}}$ & 87 & 8 & & & \\
\hline NRI & -0.6935 & 0.3355 & & & \\
\hline NTI & -0.8395 & -0.6839 & & & \\
\hline
\end{tabular}

Significant values are marked by asterisks at the probability level $(P<0.05)$.

3.2. Alien Plant Phylogenetic Signals for Functional Attributes. As revealed by the NRI/NTI indices (Table 2), the following functional attributes showed remarkable phylogenetic clustering patterns, including introduction pathway (except human-mediated species, indicated by negative values in both metrics), the life form (except liane species, indicated by negative values in both metrics), and flowering time (except summer flowering species, indicated by negative values in both metrics) for the alien species. In contrast, it was found that both the origin of distribution (except America-originated species, indicated by positive values in both metrics) and reproduction mode of alien species had phylogenetic overdispersion patterns in principle (Table 2).

The phylogenetic signal tests using Pagel's $\lambda$ statistic and Blomberg et al's $K$ statistic basically verified the findings for independent functional attributes (Table 3), but there existed some inconsistencies as well. For Pagel's $\lambda$ statistic, life form was found to have marginally significant phylogenetic signal, but NRI/NTI indices and Blomberg et al's $K$ statistic supported the existence of significant phylogenetic signal. In contrast, both Pagel's $\lambda$ and Blomberg et al's $K$ statistics identified that the origin of distribution processed significant phylogenetic clustering patterns, while NRI/NTI indices supported phylogenetic overdispersion patterns. Except the previous cases, all methods consistently identified phylogenetic clustering patterns in other functional attributes (Tables 2 and 3$)$.
3.3. Relative Importance of Phylogenetic and Functional Constraints Structuring Alien Distribution. The partial Mantel test only had a significant result for the correlation between species' Sorensen's distributional dissimilarity (calculated from species-site matrix) and phylogenetic distance matrices from $D_{\mathrm{nn}}$ index when functional dendrogram was created using Ward method (Table 4). Such a significant correlation between phylogenetic distance (from $D_{\mathrm{pw}}$ index) and distributional dissimilarity matrices was found again in another situation when functional clustering of species was recalculated using the average method. Across all the partial Mantel tests when different clustering algorithms were introduced for calculating functional distance matrix, there were no significant correlations between distributional distance and functional distance matrices (Table 4).

\section{Discussion}

Alien plants, including their distribution and ecological/ economic implications in China, have been broadly studied previously $[15,25,26,34]$. Compared to these pervious studies, the present study made a first attempt to reveal the association of distributional patterns and functional attributes of the species by considering both phylogenetic and functional relatedness of species. Three methods for testing phylogenetic clusering signals consistently identified that the 
TABLE 3: Phylogenetic signal tests using Pagel's $\lambda$ and Blomberg et al's $K$ statistics for different functional attributes of alien species of China.

\begin{tabular}{lccccc}
\hline Attributes & \multicolumn{2}{c}{$\begin{array}{c}\text { Pagel's } \lambda \\
\text { Log likelihood }\end{array}$} & $P$ & \multicolumn{2}{c}{ Blomberg et al's $K$} \\
\hline Origin of distribution & 0.252 & -156.06 & 0.02 & 0.538 & 0.001 \\
Flowering time & 0.389 & -118.85 & 0.004 & 0.453 & 0.022 \\
Life form & 0.863 & -120.95 & 0.055 & 0.516 & 0.004 \\
Introduction pathway & 0.559 & -130.09 & 0.001 & 0.517 & 0.004 \\
Reproduction mode & 0 & -13.08 & 1 & 0.314 & 0.437 \\
\hline
\end{tabular}

TABLE 4: The influence of alternative clustering methods for functional dendrogram of species on influencing the results of partial Mantel test. Values inside the parentheses were the $P$ values derived from 1000 permutation test. Values outside the parentheses were the standardized Mantel statistic. Four distance indices were applied to both phylogenetic tree and functional dendrogram as showed in the text: Sorensen, Unifrac, $D_{\mathrm{pw}}$, and $D_{\mathrm{nn}}$.

\begin{tabular}{lcccccc}
\hline & \multicolumn{2}{c}{ Ward } & \multicolumn{2}{c}{ Average } & \multicolumn{2}{c}{ Complete } \\
Indices & $\begin{array}{c}\text { Phylogenetic } \\
\text { distance versus } \\
\text { compositional } \\
\text { distance }\end{array}$ & $\begin{array}{c}\text { Functional } \\
\text { distance versus } \\
\text { compositional } \\
\text { distance }\end{array}$ & $\begin{array}{c}\text { Phylogenetic } \\
\text { distance versus } \\
\text { compositional } \\
\text { distance }\end{array}$ & $\begin{array}{c}\text { Functional } \\
\text { distance versus } \\
\text { compositional } \\
\text { distance }\end{array}$ & $\begin{array}{c}\text { Phylogenetic } \\
\text { distance versus } \\
\text { compositional } \\
\text { distance }\end{array}$ & $\begin{array}{c}\text { distance versus } \\
\text { compositional } \\
\text { distance }\end{array}$ \\
\hline Sorensen & $-0.090(0.841)$ & $0.093(0.132)$ & $-0.053(0.767)$ & $0.058(0.208)$ & $-0.078(0.821)$ & $0.0804(0.171)$ \\
$D_{\text {pw }}$ & $0.191(0.064)$ & $-0.183(0.936)$ & $0.226(0.027)$ & $-0.220(0.973)$ & $0.177(0.078)$ & $-0.168(0.918)$ \\
$D_{\text {nn }}$ & $0.189(0.039)$ & $-0.181(0.948)$ & $-0.107(0.844)$ & $0.125(0.108)$ & $0.160(0.077)$ & $-0.148(0.921)$ \\
Unifrac & $-0.223(0.948)$ & $1.178(0.948)$ & $-0.249(0.98)$ & $0.178(0.091)$ & $-0.226(0.965)$ & $0.177(0.071)$ \\
\hline
\end{tabular}

life form, flowering time, introduction pathway, and provincial distribution had strong phylogenetic clustering signals, while reproduction mode did not present any phylogenetic clustering signals. Origin of range of species did not present strong phylogenetic clustering structure, because NRI/NTI indices failed to identify possible phylogenetic clustering structure for it. As such, not all the functional attributes presented phylogenetic signals, contradictory to the second prediction.

\subsection{Phylogenetic versus Functional Constraints on Alien Plant} Community Structure. Through partial Mantel tests, it was ascertained that phylogenetic constraint played a more important role shaping alien species distribution patterns in China. The conclusion was still valid even when I considered performing different clustering strategies (including Ward, average, and complete methods) to obtain different functional dendrograms and recalculate functional diversity and distances matrix. The role of functional constraint could not be observed throughout, but the significant signal of phylogenetic constraint emerged in two situations (Table 4). This result further supported the first hypothesis, indicating that phylogeny of species has played a vital role on structuring alien plants' distribution.

4.2. On the Comparison of Different Methods for Measuring Phylogenetic Signals. NRI/NTI indices were more feasible for evaluating phylogenetic signal patterns for categorical or discrete data since their calculations could allow checking the clustering patterns of a single category of a trait. However, the indices are not applicable to continuous traits.
Pagel's $\lambda$ and Blomberg et al.'s $K$ statistics are more general and could be applied to both discrete and continuous data. They provided an overall evaluation of phylogenetic signals of species distribution across communities. However, these tests did not separate each category of a trait and investigate individual clustering/overdispersion patterns. The potential issue of doing so as NRI/NTI indices was that the dependence of communities could not be taken into account.

There were some incongruent aspects among three methods (Tables 2 and 3). Therefore, it was recommended to utilize different methods for comparison so as to ensure the accurate detection of phylogenetic signals in the trait data.

\section{Acknowledgments}

The author is grateful to Dr. Xiangcheng Mi (Institute of Botany, Chinese Academy of Sciences) for his helpful comments and polishing on an earlier version of the paper. Associate editors and anonymous reviewers are appreciated too for their constructive comments. The work was supported by the University of British Columbia.

\section{References}

[1] P. A. Tecco, S. Díaz, M. Cabido, and C. Urcelay, "Functional traits of alien plants across contrasting climatic and land-use regimes: do aliens join the locals or try harder than them?" Journal of Ecology, vol. 98, no. 1, pp. 17-27, 2010.

[2] A. Ordonez, I. J. Wright, and H. Olff, "Functional differences between native and alien species: a global-scale comparison," Functional Ecology, vol. 24, no. 6, pp. 1353-1361, 2010. 
[3] S. Knapp and I. Kühn, "Origin matters: widely distributed native and non-native species benefit from different functional traits," Ecology Letters, vol. 15, pp. 696-703, 2012.

[4] C. Ricotta, S. Godefroid, and D. Rocchini, "Invasiveness of alien plants in Brussels is related to their phylogenetic similarity to native species," Diversity and Distributions, vol. 16, no. 4, pp. 655-662, 2010.

[5] C. Ricotta, D. Heathfield, Godefroid, and S. Mazzoleni, "The effects of habitat filtering on the phylogenetic structure of the urban flora of Brussels (Belgium)," Community Eology, vol. 13, pp. 97-101, 2012.

[6] C. Ricotta, F. A. La Sorte, P. Pyšek, G. L. Rapson, L. CelestiGrapow, and K. Thompson, "Phyloecology of urban alien floras," Journal of Ecology, vol. 97, no. 6, pp. 1243-1251, 2009.

[7] M. W. Cadotte, M. A. Hamilton, and B. R. Murray, "Phylogenetic relatedness and plant invader success across two spatial scales," Diversity and Distributions, vol. 15, no. 3, pp. 481-488, 2009.

[8] K. Safi, M. V. Cianciaruso, R. D. Loyola, D. Brito, K. ArmourMarshall, and J. A. F. Diniz-Filho, "Understanding global patterns of mammalian functional and phylogenetic diversity," Philosophical Transactions of the Royal Society B, vol. 366, no. 1577, pp. 2536-2544, 2011.

[9] J. A. F. Diniz-Filho, M. V. Cianciaruso, T. F. Rangel, and L. M. Bini, "Eigenvector estimation of phylogenetic and functional diversity," Functional Ecology, vol. 25, no. 4, pp. 735-744, 2011.

[10] N. Swenson, D. Erickson, and X. Mi, "Phylogenetic and functional alpha and beta diversity in temperate and tropical tree communities," Ecology, vol. 93, pp. S112-S125, 2012.

[11] V. Devictor, D. Mouillot, C. Meynard, F. Jiguet, W. Thuiller, and N. Mouquet, "Spatial mismatch and congruence between taxonomic, phylogenetic and functional diversity: the need for integrative conservation strategies in a changing world," Ecology Letters, vol. 13, no. 8, pp. 1030-1040, 2010.

[12] D. F. B. Flynn, N. Mirotchnick, M. Jain, M. I. Palmer, and S. Naeem, "Functional and phylogenetic diversity as predictors of biodiversity- Ecosystem-function relationships," Ecology, vol. 92, no. 8, pp. 1573-1581, 2011.

[13] M. W. Cadotte, J. Cavender-Bares, D. Tilman, and T. H. Oakley, "Using phylogenetic, functional and trait diversity to understand patterns of plant community productivity," PLoS ONE, vol. 4, no. 5, Article ID e5695, 2009.

[14] E. W. Seabloom, C. D. Benfield, E. T. Borer, A. G. Stanley, T. N. Kaye, and P. W. Dunwiddie, "Provenance, life span, and phylogeny do not affect grass species' responses to nitrogen and phosphorus," Ecological Applications, vol. 21, no. 6, pp. 21292142, 2011.

[15] E. Weber, S.-G. Sun, and B. Li, "Invasive alien plants in China: diversity and ecological insights," Biological Invasions, vol. 10, no. 8, pp. 1411-1429, 2008.

[16] P. J. Prentis, J. R. U. Wilson, E. E. Dormontt, D. M. Richardson, and A. J. Lowe, "Adaptive evolution in invasive species," Trends in Plant Science, vol. 13, no. 6, pp. 288-294, 2008.

[17] D. Clements and A. Ditommaso, "Climate change and weed adaptation: can evolution of invasive plants lead to greater range expansion than forecasted?" Weed Research, vol. 51, no. 3, pp. 227-240, 2011.

[18] C. O. Webb, D. D. Ackerly, M. A. McPeek, and M. J. Donoghue, "Phylogenies and community ecology," Annual Review of Ecology and Systematics, vol. 33, pp. 475-505, 2002.
[19] C. Ricotta, S. Godefroid, and D. Rocchini, "Invasiveness of alien plants in Brussels is related to their phylogenetic similarity to native species," Diversity and Distributions, vol. 16, no. 4, pp. 655-662, 2010.

[20] P. Gerhold, M. Pärtel, O. Tackenberg et al., "Phylogenetically poor plant communities receive more alien species, which more easily coexist with natives," American Naturalist, vol. 177, no. 5, pp. 668-680, 2011.

[21] C. C. Davis, C. G. Willis, R. B. Primack, and A. J. MillerRushing, "The importance of phylogeny to the study of phenological response to global climate change," Philosophical Transactions of the Royal Society B, vol. 365, no. 1555, pp. 32023213, 2010

[22] J. D. Parker, D. E. Burkepile, M. J. Lajeunesse, and E. M. Lind, "Phylogenetic isolation increases plant success despite increasing susceptibility to generalist herbivores," Diversity and Distributions, vol. 18, no. 1, pp. 1-9, 2012.

[23] K. Harvey, D. Nipperess, D. Britton, and L. Hughes, "Australian family ties: does a lack of relatives help invasive plants escape natural enemies?" Biological Invasions, vol. 14, pp. 2423-2434, 2012.

[24] O. L. Petchey and K. J. Gaston, "Functional diversity (FD), species richness and community composition," Ecology Letters, vol. 5, no. 3, pp. 402-411, 2002.

[25] Z.-B. Wang, Y.-F. Chen, and Y.-H. Chen, "Functional grouping and establishment of distribution patterns of invasive plants in china using self-organizing maps and indicator species analysis," Archives of Biological Sciences, vol. 61, no. 1, pp. 71-78, 2009.

[26] J. Liu, S.-C. Liang, F.-H. Liu, R.-Q. Wang, and M. Dong, "Invasive alien plant species in China: regional distribution patterns," Diversity and Distributions, vol. 11, no. 4, pp. 341-347, 2005.

[27] X. Yan, H. Shou, and J. Ma, "The problem and status of the alien invasive plants in China," Plant Diversity and Resources, vol. 34, pp. 287-313, 2012.

[28] X. Wu, J. Luo, J. Chen, and B. Li, "Spatial patterns of invasive alien plants in China and its relationship with environmental and anthropological factors," Journal of Plant Ecology, vol. 30, pp. 576-584, 2006.

[29] D. Ackerly, "Conservatism and diversification of plant functional traits: evolutionary rates versus phylogenetic signal," Proceedings of the National Academy of Sciences of the United States of America, vol. 106, no. 2, pp. 19699-19706, 2009.

[30] M. A. Hamilton, B. R. Murray, M. W. Cadotte et al., "Life-history correlates of plant invasiveness at regional and continental scales," Ecology Letters, vol. 8, no. 10, pp. 1066-1074, 2005.

[31] C. O. Webb, D. D. Ackerly, and S. W. Kembel, "Phylocom: software for the analysis of phylogenetic community structure and trait evolution," Bioinformatics, vol. 24, no. 18, pp. 2098 2100,2008

[32] M. Pagel, "Inferring the historical patterns of biological evolution," Nature, vol. 401, no. 6756, pp. 877-884, 1999.

[33] S. P. Blomberg, T. Garland Jr., and A. R. Ives, "Testing for phylogenetic signal in comparative data: behavioral traits are more labile," Evolution, vol. 57, no. 4, pp. 717-745, 2003.

[34] Q.-Q. Huang, G.-X. Wang, Y.-P. Hou, and S.-L. Peng, "Distribution of invasive plants in China in relation to geographical origin and life cycle," Weed Research, vol. 51, no. 5, pp. 534-542, 2011. 
[35] J. N. Barney, T. H. Whitlow, and A. J. Lembo Jr., "Revealing historic invasion patterns and potential invasion sites for two non-native plant species," PLoS ONE, vol. 3, no. 2, Article ID e1635, 2008.

[36] E. García-Berthou, C. Alcaraz, Q. Pou-Rovira, L. Zamora, G. Coenders, and C. Feo, "Introduction pathways and establishment rates of invasive aquatic species in Europe," Canadian Journal of Fisheries and Aquatic Sciences, vol. 62, no. 2, pp. 453463, 2005.

[37] C. O. Webb and M. J. Donoghue, "Phylomatic: tree assembly for applied phylogenetics," Molecular Ecology Notes, vol. 5, no. 1, pp. 181-183, 2005.

[38] B. Bremer, K. Bremer, M. W. Chase et al., "An update of the Angiosperm Phylogeny Group classification for the orders and families of flowering plants: APG III," Botanical Journal of the Linnean Society, vol. 161, no. 2, pp. 105-121, 2009.

[39] J. Huang, B. Chen, C. Liu, J. Lai, J. Zhang, and K. Ma, "Identifying hotspots of endemic woody seed plant diversity in China," Diversity and Distributions, vol. 18, pp. 673-688, 2012.

[40] S.-B. Zhang, J. W. F. Slik, J.-L. Zhang, and K.-F. Cao, "Spatial patterns of wood traits in China are controlled by phylogeny and the environment," Global Ecology and Biogeography, vol. 20, no. 2, pp. 241-250, 2011.

[41] N. Wikström, V. Savolainen, and M. W. Chase, "Evolution of the angiosperms: calibrating the family tree," Proceedings of the Royal Society B, vol. 268, no. 1482, pp. 2211-2220, 2001.

[42] N. G. Swenson, "Phylogenetic beta diversity metrics, trait evolution and inferring the functional beta diversity of communities," PLoS ONE, vol. 6, no. 6, Article ID e21264, 2011.

[43] J. Trindade-Filho, F. L. Sobral, M. V. Cianciaruso, and R. D. Loyola, "Using indicator groups to represent bird phylogenetic and functional diversity," Biological Conservation, vol. 146, no. 1, pp. 155-162, 2012.

[44] C. N. Meynard, V. Devictor, D. Mouillot, W. Thuiller, F. Jiguet, and N. Mouquet, "Beyond taxonomic diversity patterns: how do $\alpha, \beta$ and $\gamma$ components of bird functional and phylogenetic diversity respond to environmental gradients across France?" Global Ecology and Biogeography, vol. 20, no. 6, pp. 893-903, 2011.

[45] N. Pei, J.-Y. Lian, D. L. Erickson et al., "Exploring treehabitat associations in a Chinese subtropical forest plot using a molecular phylogeny generated from DNA barcode loci," PLOS ONE, vol. 6, no. 6, Article ID e21273, 2011.

[46] J. Zhang, N. Swenson, S. Chen et al., "Phylogenetic beta diversity in tropical forests: implications for the roles of geographical and environmental distance," Journal of Systematics and Evolution, vol. 51, pp. 71-85, 2013.

[47] H. Tuomisto and K. Ruokolainen, "Analyzing or explaining beta diversity? Understanding the targets of different methods of analysis," Ecology, vol. 87, no. 11, pp. 2697-2708, 2006.

[48] K. Ruokolainen and H. Tuomisto, "Beta-diversity in tropical forests," Science, vol. 297, no. 5586, pp. 1439-1439, 2002. 

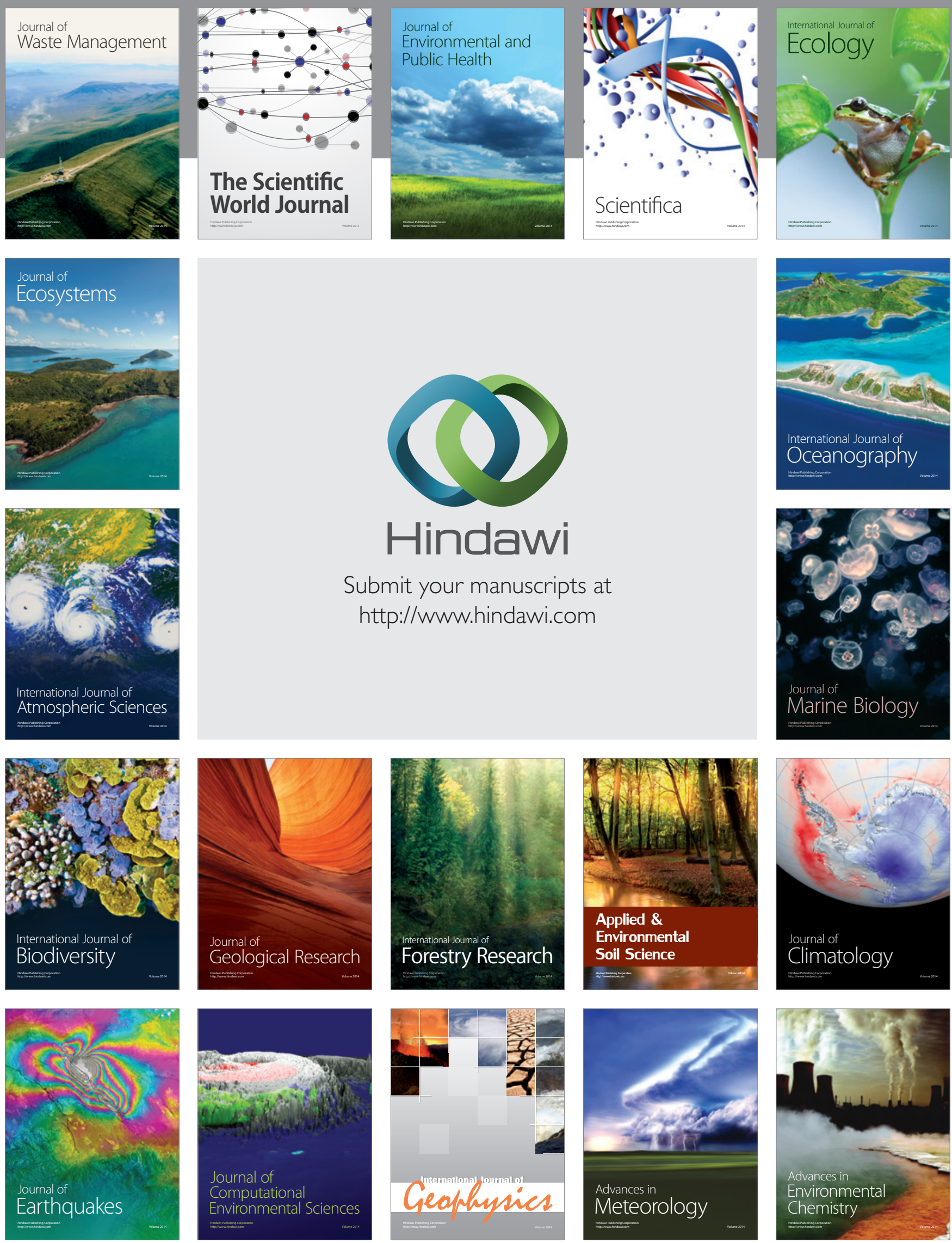